\title{
Teratogenic Effects of Crude Ethanolic Root Bark and Leaf Extracts of Rauwolfia vomitoria (Apocynaceae) on the Femur of Albino Wistar Rat Fetuses
}

\author{
Mokutima A. Eluwa, ${ }^{1}$ Theresa B. Ekanem, ${ }^{1}$ Paul B. Udoh, ${ }^{2}$ Moses B. Ekong, ${ }^{3}$ \\ Amabe O. Akpantah, ${ }^{1}$ Olaitan R. Asuquo, ${ }^{1}$ and Agnes O. Nwakanma ${ }^{4}$ \\ ${ }^{1}$ Department of Anatomy, Faculty of Basic Medical Sciences, University of Calabar, PMB 1115 Calabar, Nigeria \\ ${ }^{2}$ Department of Zoology and Environmental Biology, Faculty of Natural and Applied Sciences, University of Calabar, \\ PMB 1115 Calabar, Nigeria \\ ${ }^{3}$ Department of Anatomy, Faculty of Basic Medical Sciences, University of Uyo, PMB 1017 Uyo, Nigeria \\ ${ }^{4}$ Department of Anatomy, Faculty of Basic Medical Sciences, Anambra State University, Uli, Nigeria \\ Correspondence should be addressed to Moses B. Ekong; mbe_flashpoint@yahoo.com
}

Received 4 April 2013; Revised 20 June 2013; Accepted 21 June 2013

Academic Editor: Francesco Cappello

Copyright ( 2013 Mokutima A. Eluwa et al. This is an open access article distributed under the Creative Commons Attribution License, which permits unrestricted use, distribution, and reproduction in any medium, provided the original work is properly cited.

\begin{abstract}
Introduction. Rauwolfia vomitoria is a plant used as a sedative and in the treatment of psychotic tendency. This study was on the teratogenic effects of its root bark and leaf extracts on Wistar rat's fetal femurs. Materials and Methods. Twenty-five female rats weighing between 180 and 200 g were divided into 5 groups, of 5 rats each. Group A was the control, while Groups B, C, D, and E were the experimental. The female rats were mated with mature male rats to allow for pregnancy. Groups $\mathrm{B}$ and $\mathrm{C}$ animals received orally $150 \mathrm{mg} / \mathrm{kg}$ each of the root bark and leaf extracts of Rauwolfia vomitoria, respectively, while Groups D and E animals received $250 \mathrm{mg} / \mathrm{kg}$ bodyweight each of the root bark and leaf extracts of Rauwolfia vomitoria, respectively, from day 7 to day 11 of gestation. On day 20 of gestation, the rats were sacrificed, the fetuses were examined, and their femurs were dissected out and preserved, decalcified, and routinely processed using the Haematoxylin and Eosin staining method. Results. Histological observations of the fetal femur bones showed numerous osteoblast and osteoclast, hypertrophy, and hyperplasia of bone cells compared with the control. Conclusion. Ethanolic root bark and leaf extracts of Rauwolfia vomitoria may lead to advanced skeletal development.
\end{abstract}

\section{Introduction}

Herbalism has become the main stream throughout the world. This is due in part to the recognition of the value of traditional medical systems, particularly of the Asian origin, and the identification of medicinal plants from indigenous pharmacopeias shown to have significant healing power, either in their natural state or as the source of new pharmaceuticals. Generally, these formulations are considered moderate in efficacy and thus less toxic than most synthetic pharmaceutical agents [1].

One of such herbs in use is Rauwolfia vomitoria belonging to the family Apocynaceae. Reports show that this herb lowers blood pressure [2] and possesses analgesic, haematinic, and anticonvulsant properties [3-5]. Antioxidant and antipsychotic properties have also been reported $[6,7]$, with another study reporting improvement of immunity [8]. Rauwolfia is reported to contain indole alkaloids which includes yohimbine, reserpine, rescinnamine, raucaffricine, ajmaline, and ajmalicine [9]. These may be responsible for the different properties exhibited by the plant.

Common herbs rich in essential oils (sage, rosemary, and thyme) and essential oils extracted from these herbs and other plants (oils of sage, rosemary, juniper, pine, dwarf pine, turpentine, and eucalyptus) as well as their monoterpene components (thujone, eucalyptol, camphor, borneol, thymol, $\alpha$-pinene, $\beta$-pinene, bornyl acetate, and menthol) were found to inhibit bone resorption when added to the food of rats. Pine oil, used as a representative essential oil, protects an 
osteoporosis model, the aged ovariectomized rat, from bone loss, while the monoterpenes borneol, thymol, and camphor are directly inhibitory in the osteoclast resorption pit assay [10].

Bones are rigid organs that form part of the endoskeleton of vertebrates. They are dense connective tissues that function to move, support, and protect the various organs of the body, produce red and white blood cells, and store minerals. Because bones come in variety of shapes and have complex internal and external structures, they are lightweight, yet strong and hard, in addition to fulfilling their many other functions. One of the types of tissues that makes up bone is the mineralized osseous tissues, also called bone tissue, that gives it rigidity and a honeycomb-like three-dimensional internal structure. Other types of tissues found in bones include marrow, endosteum and periosteum, nerves, blood vessels, and cartilage. There are 206 bones in the adult human body and 270 in an infant $[11,12]$.

Bone contains an extracellular mineralized matrix and a number of different cell types, including osteoblasts, osteocytes, and osteoclasts. The bone matrix consists of a ground substance in which numerous collagen fibers are embedded, usually ordered in bone in parallel arrays. In mature bone, the matrix is moderately hydrated, and $10 \%-20 \%$ of its mass is water. Of its dry weight, $60 \%-70 \%$ is made up of inorganic, mineral salts (mainly microcrystalline, calcium and phosphate hydroxides, hydroxyapatite), $30 \%-40 \%$ is collagen and the remainder (c. 5\%) is noncollagenous protein and carbohydrate, mainly conjugated as glycoproteins. The proportions of these various components vary with age, location, and metabolic status [11].

Rauwolfia vomitoria has been used for centuries in India and Africa for the treatment of a variety of disorders including snake bites, insect bites and stings, insomnia, and maniac tendency, but the safety and efficacy of its use in pregnancy have not been established. Thus, this study was carried out to investigate the teratogenic effect of crude ethanolic root bark and leaf extracts of Rauwolfia vomitoria on the histology of developing femur bone to assess skeletal development.

\section{Materials and Methods}

Twenty-five adult female Wistar rats were bred in the Animal House of the Department of Human Anatomy, University of Calabar, after ethical approval was obtained from the Ethical Board of the University of Calabar. The animals were treated according to the International Guidelines for the Treatment of Animals and fed with normal rat chow, and water was provided ad libitum throughout the duration of the experiment. The rats were kept under standard room temperature of $25-27^{\circ} \mathrm{C}$. The animals were divided into five groups designated as A, B, C, D, and E each consisting of five rats. Group A animals were the control and groups B, C, D, and $\mathrm{E}$ were the experimental animals.

2.1. Preparation of the Herb Extract. The roots and leaves of Rauwolfia vomitoria tree were collected from Ekpene Obo, Esit Eket Local Government Area, Akwa Ibom State, Nigeria, and were identified and authenticated by the botanist in the Botanical Garden of the University of Calabar, Nigeria. The roots and the leaves were washed with water to remove the impurities. The root barks were defoliated and dried in carbolite moisture extraction drying oven (Grant Instruments, Cambridge, $\mathrm{UK}$ ) at $40^{\circ} \mathrm{C}-50^{\circ} \mathrm{C}$, and the leaves were defoliated and dried for 3 hours. The dried root bark and leaf were blended into powder using a Binatone kitchen blender and kept in glass containers with plastic covers. The extraction method involved cold ethanolic extraction, where a known weight of the blended sample was soaked in ethanol for 24 hours, and then the extract was filtered and evaporated to dryness at room temperature to obtain the crude extract.

2.2. Experimental Protocol. The twenty-five virgin female Wistar rats were caged with sexually mature male rats of the same strain overnight after ascertaining the estrous phase of the estrous cycle. The presence of tailed structures in the vaginal smear the following morning confirmed coitus, and the sperm-positive day was designated as day zero of pregnancy. Oral doses of $150 \mathrm{mg} / \mathrm{kg}$ root bark and leaf extracts of Rauwolfia vomitoria were administered to pregnant rats in groups $\mathrm{B}$, and $\mathrm{C}$, respectively, while Groups $\mathrm{D}$ and $\mathrm{E}$ respectively were treated with $250 \mathrm{mg} / \mathrm{kg}$ per body weight of ethanolic root bark and leaf extracts. The treatments spanned from the 7th the through 11th day of gestation with the aid of an orogastric tube. The control, Group A, animals received corresponding volumes of distilled water on the corresponding days of gestation.

The pregnancy was terminated on the 20th day of gestation by chloroform inhalation method, and the fetuses were collected by uterectomy. The fetuses were blotted dry and examined for gross malformations. Fetuses were weighed by Libror EB-330H sensitive balance. The fetal femurs were extracted with the aid of a sharp needle and a forceps. The femurs were then fixed in buffered formalin and then decalcified using 4\% formic acid. Complete decalcification was tested by using ammonium oxalate solution which when dropped in the decalcifying agent turns cloudy if decalcification is not complete.

Routine histological processing using Haematoxylin and Eosin staining method was carried out. The stained tissues on slides were mounted on a light microscope at $\times 400$ magnification and were quantified to determine the population of osteoblasts and osteocytes within the bone matrix using ImageJ. The slides were further processed into micrographs, and the photomicrographs were obtained at $\times 400$ magnification.

\section{Results}

Histological study of the fetal femur bone using Haematoxylin and Eosin staining method showed that Group A (control), bone matrix contained numerous osteoblasts (Figure 1). Groups B and C whose mothers received $150 \mathrm{mg} / \mathrm{kg}$ of the root bark and leaf extracts of Rauwolfia vomitoria,respectively, showed numerous osteoblasts and osteocytes in the histological sections (Figures 2 and 3). In 


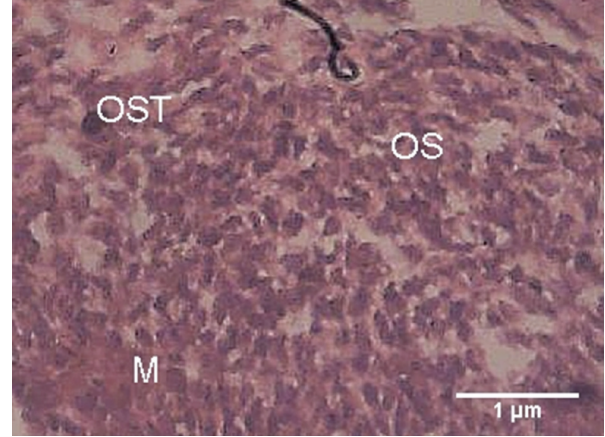

FIGURE 1: Photomicrograph of the control group showing fetal femur bone section with bone matrix $(\mathrm{M})$ containing osteoblasts (OS) and osteocytes (OST) $(\mathrm{H} \& \mathrm{E} \times 400)$.

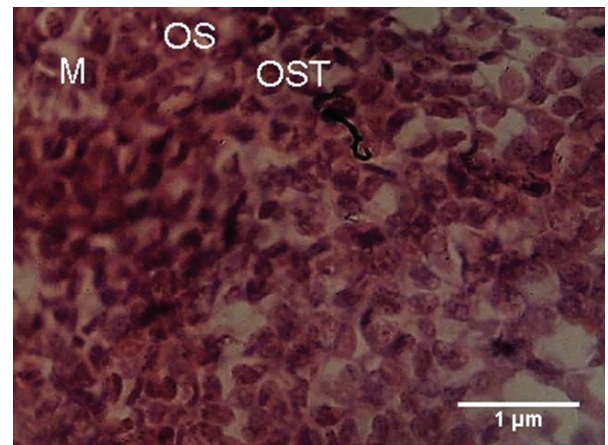

FIgURE 2: Photomicrograph of the fetal femur bone of Group B treated with $150 \mathrm{mg} / \mathrm{kg}$ of root bark extract showing the matrix (M) with enlarged osteoblasts (OS) and osteocytes (OST) $(\mathrm{H} \& \mathrm{E} \times 400)$.

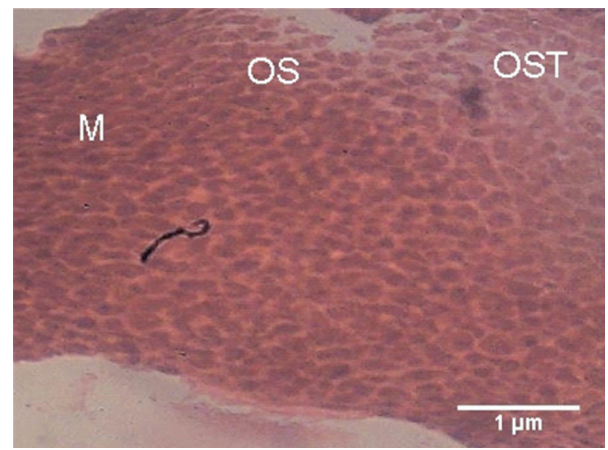

FIGURE 3: Photomicrograph of the fetal femur bone of Group C treated with $150 \mathrm{mg} / \mathrm{kg}$ of leaf extract showing the matrix (M) with numerous osteoblasts (OS) and osteocytes (OST) $(\mathrm{H} \& \mathrm{E} \times 400)$.

Group D that received $250 \mathrm{mg} / \mathrm{kg}$ of the root bark extract of Rauwolfia vomitoria, there was increase in the bone matrix with scanty osteoblasts when compared with the control (Figure 4). Hypertrophy and hyperplasia of bone cells, osteoblast, and osteocytes were seen in Group E animals whose mothers received $250 \mathrm{mg} / \mathrm{kg}$ of the leaf extract of Rauwolfia vomitoria (Figure 5).

The osteoblast population within the bone matrix of Group A (control) sections was significantly $(P<0.05)$ lower

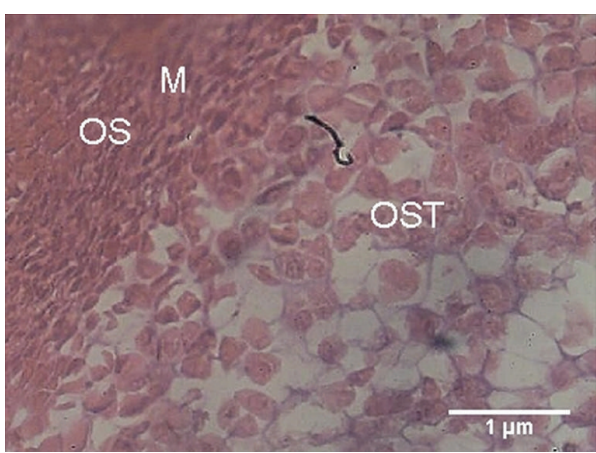

FIgURe 4: Photomicrograph of the fetal femur bone of Group D treated with $250 \mathrm{mg} / \mathrm{kg}$ of root bark extract showing scanty osteoblasts (OS) within the bone matrix $(\mathrm{H} \& \mathrm{E} \times 400)$.

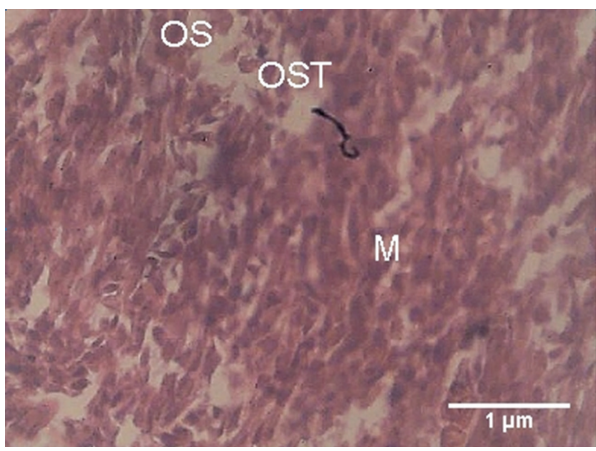

Figure 5: Photomicrograph of the fetal femur bone of Group E treated with $250 \mathrm{mg} / \mathrm{kg}$ of leaf extract showing numerous osteoblasts (OS) and osteocytes (OST) $(\mathrm{H} \& \mathrm{E} \times 400)$.

TABLE 1: Bone matrix population of osteoblasts and osteocytes.

\begin{tabular}{lcc}
\hline Group $(n=5)$ & Osteoblast & Osteocyte \\
\hline Control (Group A) & $117 \pm 0.71$ & $143 \pm 0.71$ \\
Group B & $155 \pm 0.86^{*}$ & $99 \pm 1.41^{*}$ \\
Group C & $285 \pm 3.54^{*, \mathrm{~b}, \mathrm{~d}, \mathrm{e}}$ & $191 \pm 2.83^{*, \mathrm{~b}, \mathrm{~d}, \mathrm{e}}$ \\
Group D & $111 \pm 1.14^{\mathrm{NS}}$ & $88 \pm 0.71^{*}$ \\
Group E & $141 \pm 1.00^{*, \mathrm{~d}}$ & $126 \pm 2.03^{*, \mathrm{~d}}$ \\
\hline
\end{tabular}

Data presented as mean \pm standard error or mean.

${ }^{*}$ Significantly different from control group at $P<0.05$.

${ }^{\mathrm{b}}$ Significantly different from Group B at $P<0.05$.

${ }^{\mathrm{d}}$ Significantly different from Group D at $P<0.05$.

${ }^{\mathrm{e}}$ Significantly different from Group $\mathrm{E}$ at $P<0.05$.

${ }^{\mathrm{NS}}$ Not significantly different from control group at $P<0.05$.

than those of Groups B and C treated with $150 \mathrm{mg} / \mathrm{kg}$ of the root bark and leaf extracts of Rauwolfia vomitoria. The control Group osteoblasts were also significantly $(P<0.05)$ lower than those of Group E treated with $250 \mathrm{mg} / \mathrm{kg}$ leaf extract of Rauwolfia vomitoria. No difference was however observed with group D treated with $250 \mathrm{mg} / \mathrm{kg}$ root bark extract of Rauwolfia vomitoria. Group C treated with $150 \mathrm{mg} / \mathrm{kg}$ leaf extract of Rauwolfia vomitoria was significantly $(P<$ 0.05) higher than Groups B, D, and E, while Group D was significantly $(P<0.05)$ lower than Group E (Table 1$)$. 
The osteocyte population within the bone matrix of group A (control) sections was significantly $(P<0.05)$ higher than groups B, D, and E treated, respectively, with the $150 \mathrm{mg} / \mathrm{kg}$ and $250 \mathrm{mg} / \mathrm{kg}$ of root bark extracts of Rauwolfia vomitoria and $250 \mathrm{mg} / \mathrm{kg}$ of leaf extract of Rauwolfia vomitoria. They were however significantly $(P<0.05)$ lower than Groups $C$ treated with $150 \mathrm{mg} / \mathrm{kg}$ leaf extract of Rauwolfia vomitoria. Group C treated with $150 \mathrm{mg} / \mathrm{kg}$ leaf extract of Rauwolfia vomitoria was significantly $(P<0.05)$ higher than Groups $B$, $\mathrm{D}$, and $\mathrm{E}$, while Group D was significantly $(P<0.05)$ lower than group E (Table 1).

\section{Discussion}

Bone is a specialized connective tissue composed of intercellular calcified material, the bone matrix, and three cell types: osteocytes which are found in the cavities (lacunae) within the matrix; osteoblasts which synthesis the organic components of the matrix and osteoclasts which are multinucleated giant cells involved in the resorption and remodeling of bone tissue [12].

Hypertrophy and hyperplasia of osteoblasts were seen in Groups B, C, and E animals whose mothers received, respectively, $150 \mathrm{mg} / \mathrm{kg}$ of the root bark extract and $150 \mathrm{mg} / \mathrm{kg}$ and $250 \mathrm{mg} / \mathrm{kg}$ of the leaf extract Rauwolfia vomitoria. These are in correlation with the stereological quantification results in osteoblasts and osteocytes population. The results indicate that Rauwolfia vomitoria or its constituents crossed the placental barrier. These obtained results may be due to advanced skeletal development. The root bark and leaf extracts of Rauwolfia vomitoria may have crossed the placental barrier to affect the skeletal programming of femur bone development at the cellular level, thus exerting direct effect on skeletal cells. The fetal bones of the animals whose mothers received $250 \mathrm{mg} / \mathrm{kg}$ of the root bark extract were severely affected as the bone tissues were characterized by matrix with few osteoblasts, which may result in delayed ossification.

IL-1, a bone-regulating cytokine, has been shown to exert direct effect on skeletal cells $[13,14]$, which may affect cells such as chondrocytes, osteoblasts, and osteoclasts. The Rauwolfia vomitoria extracts may stimulate this cytokine resulting in the reported result of this study. Oreffo et al. [15] reported that IL-1 affects the offspring indirectly via the placenta. IL-1 exposure also results in decreased skeletal growth and a reduced amount of cortical bones in adult rats offspring [16].

The notion that skeletal growth may be programmed during intrauterine or early postnatal life is supported by a study by Cooper et al., [17] demonstrating a relationship between adult bone mass and weight at 1 year of age. In a related study, Snow and Keiver [18] reported that prenatal ethanol exposure has effect on the resting zone of the developing bone indicating that earlier stages of bone development may also be disrupted. The decrease in the length of the resting zone increased the length of the hypertrophic zone and enlarged, which was consistent with an effect of ethanol on the later stages of bone development.

In conclusion, this study suggests that the high dose of root bark extract of Rauwolfia vomitoria had an adverse effect on the developing femur rather than the leaf extract. Hence, the root bark extract may lead to skeletal retardation, while the leaf extract may advance skeletal development.

\section{Disclosure}

This research was carried out in the Department of Anatomy, Faculty of Basic Medical Sciences, University of Calabar, Calabar, Nigeria.

\section{References}

[1] M. Elvin-Lewis, "Should we be concerned about herbal remedies," Journal of Ethnopharmacology, vol. 75, no. 2-3, pp. 141-164, 2001.

[2] O. O. Amole, "Blood pressure responses to aqueous extract of Rauvolfia vomitoria (Afzel)," Nigerian Journal of Health and Biomedical Sciences, vol. 2, pp. 50-51, 2003.

[3] O. O. Amole and O. O. Ogunjere, "Evaluation of the haematological properties of the plant extract of Rauvolfia vomitoria (Afzel)," Journal of Medical Sciences, vol. 3, pp. 14-15, 2001.

[4] O. O. Amole, A. O. Onabanjo, and A. A. Odofin, "The analgesic effect of Rauvolfia vomitoria (Afzel)," Biomedical Research, vol. 17, no. 2, pp. 125-127, 2006.

[5] O. O. Amole, O. K. Yemitan, and K. A. Oshikoya, "Anticonvulsant activity of Rauvolfia vomitoria (Afzel)," African Journal of Pharmacy and Pharmacology, vol. 3, no. 6, pp. 319-322, 2009.

[6] M. I. Akpanabiatu, F. E. Uboh, T. B. Ekanem, I. B. Umoh, E. U. Eyong, and S. O. Ukafia, "The effect of interaction of Rauwolfia vomitoria root bark extract with vitamin E on rats' liver enzymes," Turkish Journal of Biology, vol. 33, no. 3, pp. 189194, 2009.

[7] S. Bisong, R. Brown, and E. Osim, "Comparative effects of Rauwolfia vomitoria and chlorpromazine on social behaviour and pain," North American Journal of Medical Sciences, vol. 3, no. 1, pp. 48-54, 2011.

[8] M. I. Akpanabiatu, O. Otitoju, E. E. Edet, J. I. Ndem, A. F. Uwah, and U. F. Ufot, "Vitamin E supplementation with rauwolfa vomitoria root bark extract improves hematological indices," North American Journal of Medical Sciences, vol. 4, no. 2, pp. 86-89, 2012.

[9] S. W. Azeem, M. A. Khan, and I. Ahmed, "Characterisation of oxidation products of Rauwofia alkaloids," Pakistan Journal of Pharmaceutical Sciences, vol. 18, pp. 33-35, 2005.

[10] R. C. Mühlbauer, A. Lozano, S. Palacio, A. Reinli, and R. Felix, "Common herbs, essential oils, and monoterpenes potently modulate bone metabolism," Bone, vol. 32, no. 4, pp. 372-380, 2003.

[11] S. D. Gentry and C. A. Bramblett, The Anatomy and Biology of the Human Skeleton, A\&M University Press, College Station, Tex, USA, 1988.

[12] C. J. Luiz and C. Jose, Basic Histology Text and Atlas, McGraw Hill, New York, NY, USA, 11th edition, 2005.

[13] G. D. Roodman, "Biology of osteoclast activation in cancer," Journal of Clinical Oncology, vol. 19, no. 15, pp. 3562-3571, 2001.

[14] S. Roux and P. Orcel, "Bone loss: factors that regulate osteoclast differentiation: an update," Arthritis Research, vol. 2, no. 6, pp. 451-456, 2000.

[15] R. O. C. Oreffo, B. Lashbrooke, H. I. Roach, N. M. P. Clarke, and C. Cooper, "Maternal protein deficiency affects mesenchymal 
stem cell activity in the developing offspring," Bone, vol. 33, no. 1, pp. 100-107, 2003.

[16] D. Swolin-Eide, C. Nilsson, A. Holmäng, and C. Ohlsson, "Prenatal exposure to IL-1 $\beta$ results in disturbed skeletal growth in adult rat offspring," Pediatric Research, vol. 55, no. 4, pp. 598603, 2004.

[17] C. Cooper, C. Fall, P. Egger, R. Hobbs, R. Eastell, and D. Barker, "Growth in infancy and bone mass in later life," Annals of the Rheumatic Diseases, vol. 56, no. 1, pp. 17-21, 1997.

[18] M. E. Snow and K. Keiver, "Prenatal ethanol exposure disrupts the histological stages of fetal bone development," Bone, vol. 41, no. 2, pp. 181-187, 2007. 

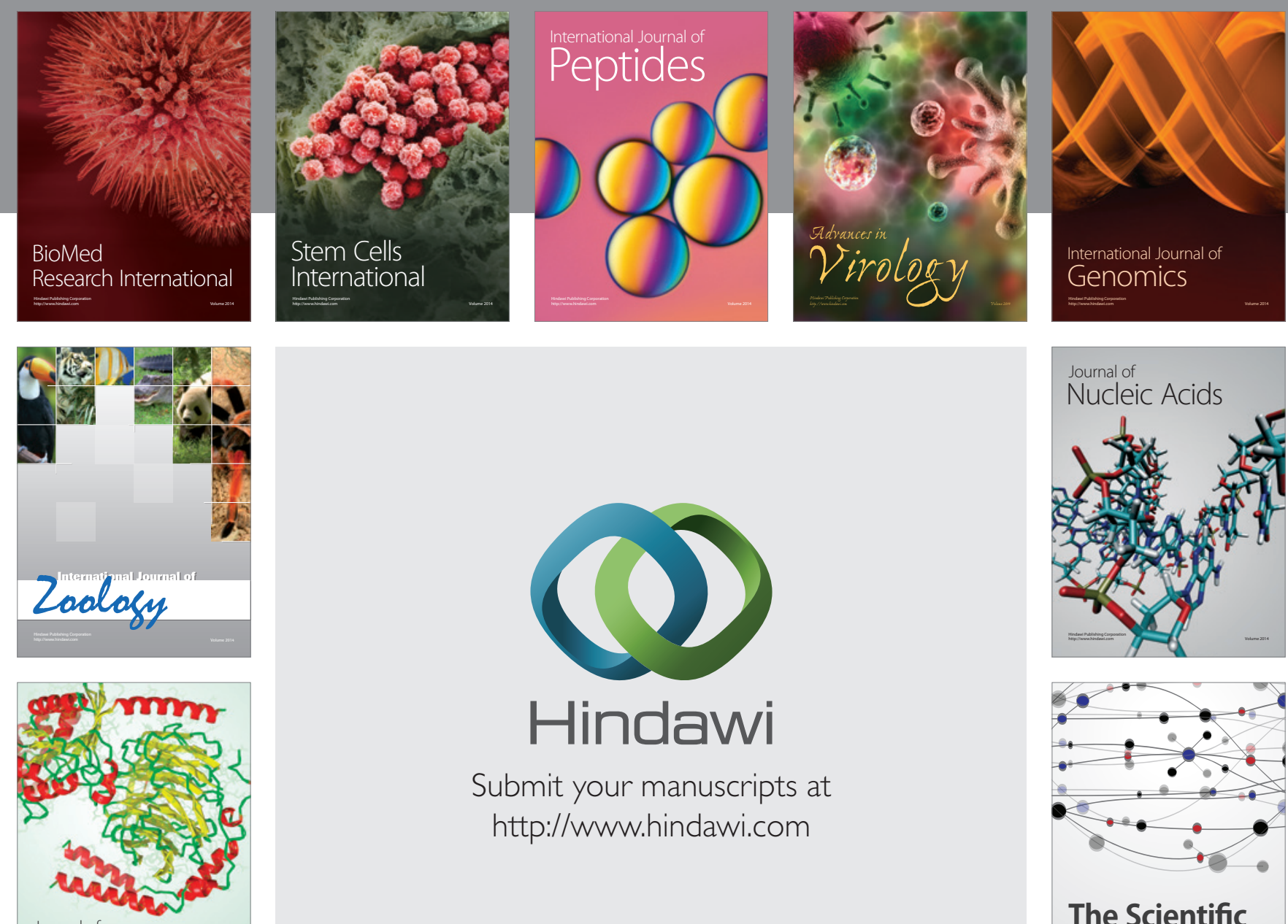

Submit your manuscripts at

http://www.hindawi.com

Journal of
Signal Transduction
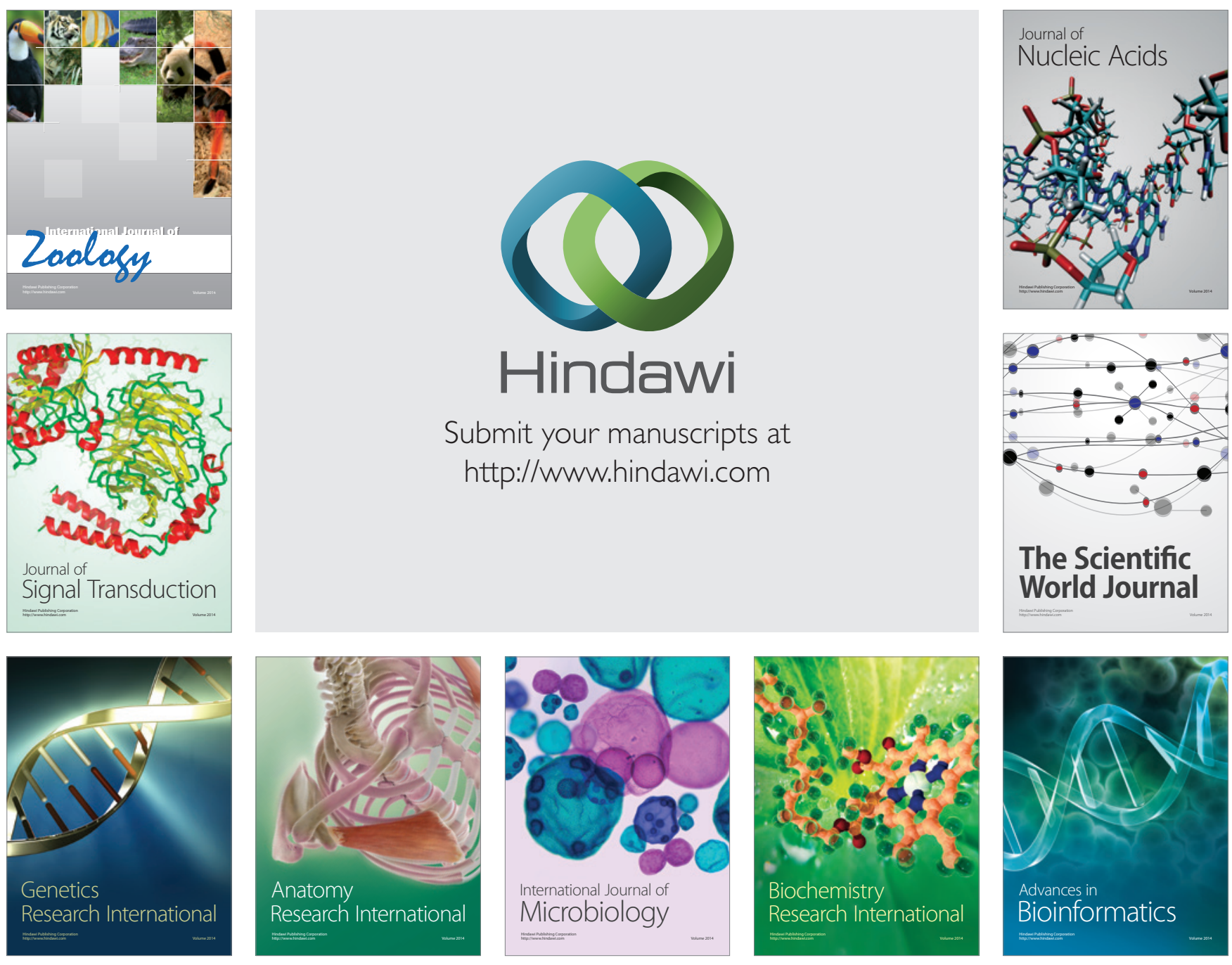

The Scientific World Journal
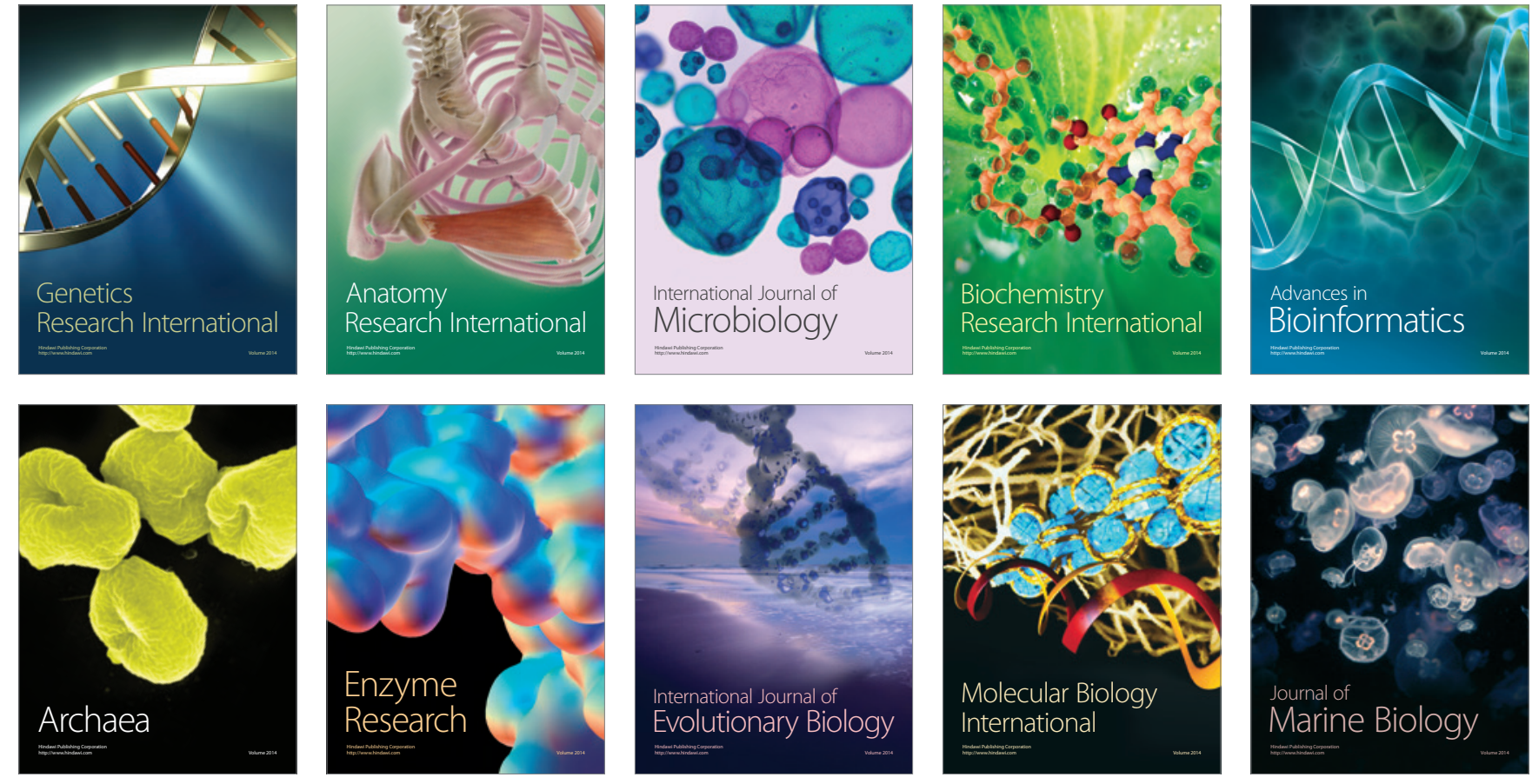